\title{
Os interesses e as regras: a Convenção de Minamata nas perspectivas do Realismo Neoclássico e Construtivismo ${ }^{1}$
}

\author{
The interests and rules: \\ the Minamata Convention in the perspectives \\ of Neoclassical Realism and Constructivism
}

DOI: $10.21530 /$ ci.v13n3.2018.780

Bruno Mendelski²
Guilherme Frizzera $^{3}$

\section{Resumo}

A Convenção de Minamata regula a questão dos efeitos do mercúrio no meio ambiente. Essa inciativa global inclui a participação de grandes potências como os EUA e a China, além de outros países em desenvolvimento e que possuem parte de sua produção voltada à mineração. A partir das perspectivas teóricas do realismo neoclássico e do construtivismo, o artigo cria um diálogo entre as duas correntes, apontando a importância tanto da questão do poder quanto da participação de importantes atores globais, quanto no papel das ideias, crenças e das normas na construção de um regime de regulação do uso e dos efeitos do mercúrio. A conclusão aponta que, além do alto custo do constrangimento pela não participação de um regime normativo do meio ambiente, o sucesso da Convenção de Minamata está na participação de Pequim e Washington. Esses países levam à participação de outros atores. Por fim, estimula-se a aproximação dos estudos de meio ambiente com os das teorias de relações internacionais.

Palavras-Chaves: Convenção de Minamata; Teoria das Relações Internacionais; Realismo Neoclássico; Construtivismo.

1 O presente trabalho foi realizado com apoio da Coordenação de Aperfeiçoamento de Pessoal de Nível Superior - Brasil (CAPES) - Código de Financiamento 001.

2 Graduado (UNILASALLE-RS), mestre (UFRGS), doutorando em Relações Internacionais (IREL/UnB) e bolsista CAPES. Professor Assistente desde 2012 do Curso de Relações Internacionais da UNISC. Atualmente é Katip Fellow (Turkish Communication Program for Public Officials and Academic Staff) e Visiting Doctoral Student at the Department of Political Science and International Relations at University of Istanbul.

3 Graduado em Relações Internacionais pelas Faculdades Integradas Rio Branco. Mestre em Integração da América Latina pela Universidade de São Paulo (PROLAM/USP). Doutorando em Relações Internacionais pela Universidade de Brasília (IREL/UnB) e bolsista CAPES.

Artigo submetido em 27/03/2018 e aprovado em 01/11/2018. 


\begin{abstract}
The Minamata Convention regulates the effects of mercury on the environment. This global initiative includes the participation of major powers such as the United States and China, as well as other developing countries, which take part in consideration of their mining-related output. From the theoretical perspectives of Neoclassical Realism and Constructivism, the article creates a dialogue between the two theoretical frameworks. Pointing out the importance of both questions of power and participation of important global actors, and the role of ideas, beliefs and norms in the construction of a regime governing the use and effects of mercury. The conclusion is, as well as the high cost of embarrassment due to the non-participation of a normative regime of the environment, the success of the Minamata Convention is in the participation of Beijing and Washington. Those countries lead other actors to participate of a regime. Finally, it stimulated the approximation of environmental studies with those of International Relations Theories.
\end{abstract}

Keywords: Minamata Convention; International Relations Theory; Neoclassical Realism; Constructivism.

\title{
Introdução
}

Os tratados, regimes e a governança internacionais são importantes fontes de análise nas relações internacionais e uma das discussões mais ricas no aspecto teórico. Diversos ângulos analíticos utilizam questões globais para que possam basear e sustentar seus avanços intelectuais na academia. Esses esforços se traduzem em correntes que, a princípio, são antagônicas, mas que, quando utilizadas para criar um debate de via média, contribuem para o enriquecimento do campo de estudo. No caso, o realismo e o construtivismo.

Jogos de poder, status quo, prestígio, poder, hard power, ganhos relativos e maximização do poder são conceitos próprios da corrente do realismo, os quais também se fazem presentes em sua abordagem neoclássica. A cooperação se sustenta a partir de uma análise racional de quem ganhará mais ao estabelecer um acordo com outro Estado. Em uma abordagem cooperativa mais abrangente, isto é, quando os acordos possuem características multilaterais ou até mesmo globais, esses assumem um outro aspecto caro para os realistas: quem criará as regras? O estabelecimento dessas regras e os efeitos coercitivos são importantes fatores para os interesses dos Estados. Outrossim, essa é uma discussão fundamental para o construtivismo nas relações internacionais. 
Focando no papel das normas e regras, o construtivismo introduz a importância da normatização no ambiente internacional. A questão de como as regras são socializadas, internalizadas ou refutadas pelos agentes, o socializador e a governança internacional em forma de instituições e organizações - ou, até mesmo, uma governança sem governo -, são as principais perguntas do construtivismo para uma discussão que envolva tratados, cooperação ou regimes internacionais. Dando uma menor importância a questão de quem irá lucrar mais em um ambiente cooperativo, o construtivismo tende a ver o benefício gerado por essas institucionalizações de uma forma geral e não específica.

A pergunta que se faz é: ao juntar as duas formas de análise, pode-se ter um panorama mais completo do que levam os agentes a cooperar e buscar a institucionalização de temas no ambiente internacional?

Para responder tal pergunta, será analisada a Convenção de Minamata sobre o uso do mercúrio pelos países. Esse importante acordo internacional possui a participação de importantes players, como os Estados Unidos e a China, assim como demais países cuja literatura poderia classificar como subdesenvolvidos ou em desenvolvimento. A discussão proposta visa integrar duas visões analíticas teóricas distintas e busca encontrar uma via média específica para a questão de Minamata. Com isso, apresentar-se um quadro de menor fragmentação no campo das teorias de relações internacionais, utilizando-se uma abordagem mais plural e contribuindo para o debate teórico da disciplina.

\section{A Convenção de Minamata}

A Convenção de Minamata é um tratado global destinado a proteger a saúde humana e o meio ambiente dos efeitos adversos do mercúrio (MINAMATA CONVENTION ON MERCURY, 2017). Para Eriksen e Perrez (2014) a apresentação, em 2001, de um estudo sobre o mercúrio pelos EUA durante a $21^{\text {a }}$ sessão do Governing Council of the United Nations Environment Programme (GC-UNEP) marca o início das articulações globais a respeito da limitação do uso do mercúrio. A reunião seguinte do GC-UNEP, em 2003, apresenta dois avanços em relação à necessidade de restrição do uso do mercúrio. O primeiro remete à constatação de que "existe suficiente evidência dos significativos impactos globais adversos do mercúrio e seus componentes para justificar novas ações internacionais para reduzir os riscos para a saúde humana e para o meio ambiente" (UNEP/GC.22/11, 
2003, p. 52, tradução livre ${ }^{4}$. Segundo: também sinaliza, pela primeira vez, a concordância dos Estados em adotar ações imediatas para mitigar o problema do mercúrio (UNEP, 2003).

Entretanto, a discussão de uma abordagem vinculante sobre o mercúrio não prosperou em razão da oposição de importantes países ricos e em desenvolvimento. EUA, Canadá, Austrália e Nova Zelândia argumentaram que um instrumento vinculante seria muito custoso e de difícil implementação, sendo mais eficiente uma abordagem voluntária (UNEP/GC.23/11, 2005). Já China e Índia sustentavam que

os países em desenvolvimento apoiavam fortemente a gestão internacional de produtos químicos [mercúrio], mas enfatizam que todas as decisões propostas sobre o assunto deveriam incluir disposições sobre transferência de tecnologia, capacitação e financiamento sustentável (UNEP, 2005, p. 63, tradução livre5).

Durante a $24^{\text {a }}$ sessão da UNEP-GC, o apoio a uma abordagem vinculante aumentou, contando com a adesão de países africanos, da União Europeia, Brasil, Japão, Rússia e Uruguai (UNEP, 2007). Em 2009, a mudança de postura dos EUA influenciou grandes players como Canadá, Austrália, China e Índia a serem mais receptivos à adoção de medidas vinculantes para a restrição do uso do mercúrio (SELIN, 2014). Como resultado, houve a decisão 25/5 do UNEP-GC de 2009, a qual demandava que os Estados iniciassem negociações para assinar um tratado sobre a contenção do uso do mercúrio (UNEP, 2009). Os encontros foram chamados de Intergovernmental Negotiating Committee e, no decorrer da quinta reunião (janeiro de 2013 em Genebra), a Convenção de Minamata foi assinada por delegados de 140 países (MINAMATA CONVENTION, 2017). Posteriormente, depois da ratificação do $51^{\circ}$ membro, o tratado entrou em vigor em outubro do mesmo ano (MINAMATA CONVENTION, 2017).

O compromisso recebeu o nome da cidade japonesa de Minamata, a qual sofreu, na década de 1950, um grande derramamento de mercúrio em sua baía, resultando na morte de 900 pessoas. No evento, 2.265 pessoas foram diagnosticadas

4 No original em inglês: "that there is sufficient evidence of significant global adverse impacts from mercury and its compounds to warrant further international action to reduce the risks to human health and the environment".

5 No original em inglês: "that developing countries strongly supported international chemicals management but stressed that all proposed decisions on the subject should include provisions on technology transfer, capacitybuilding and sustainable funding”. 
com intoxicação por mercúrio - agora conhecida como doença de Minamata (UNIDO, 2014). Até a presente data, 128 Estados assinaram a Convenção de Minamata e 98 desses a ratificaram6.

A concretização desse tratado se reveste de importância, na medida em que o mercúrio e a maioria dos seus compostos são altamente tóxicos para os seres humanos e para o meio ambiente. Sua periculosidade pode ser observada na constatação de que a ingestão de grandes quantidades do mercúrio pode ser fatal, e mesmo doses baixas podem ter graves efeitos para a saúde (EUROPEAN COMMISSION, 2017).

De acordo com o site oficial do acordo, a Convenção de Minamata procurará:

a proibição de novas minas de mercúrio, a eliminação das já existentes, a eliminação e a redução do uso de mercúrio em vários produtos e processos, medidas de controle sobre emissões para o ar e em libertações para a terra e água, e a regulamentação do setor informal de mineração de ouro artesanal e em pequena escala. A Convenção também aborda o armazenamento provisório de mercúrio e sua disposição, uma vez que se torne desperdício, locais contaminados pelo mercúrio e problemas de saúde. (MINAMATA CONVENTION, 2017)

Destarte, conforme preconiza o $1^{\circ}$ artigo do tratado, o principal objetivo da Convenção é “proteger a saúde humana e o meio ambiente das emissões antropogênicas e libertações de mercúrio e compostos de mercúrio” (MINAMATA CONVENTION, 2017). A convenção versa sobre todo o ciclo de vida do mercúrio, desde a sua extração mineral até a eliminação de seus resíduos. Para tanto, o acordo determina medidas de controle obrigatórias para todos os Estados membros. Assim, o objetivo central da Convenção de Minamata reside em eliminar, progressivamente, a adição de mercúrio aos níveis já existentes no meio ambiente e na cadeia alimentar (MINAMATA CONVENTION, 2017).

\footnotetext{
6 São eles: Afeganistão, Alemanha, Antígua e Barbuda, Argentina, Armênia, Áustria, Bélgica Benin, Bolívia, Botswana, Brasil, Bulgária, Burkina Faso, Canadá, Chade, Chile, China, Costa Rica, Croácia, Cuba, Dinamarca, Djibouti, Equador, El Salvador, Emirados Árabes Unidos, Eslováquia, Eslovênia, Estados Unidos da América, Estônia, eSwatini, Finlândia, França, Gabão, Gâmbia, Geórgia, Gana, Guiné, Guiana, Honduras, Hungria, Irã, Islândia, Índia, Indonésia, Jamaica, Japão, Jordânia, Kiribati, Kuwait, Laos, Letônia, Líbano, Lesoto, Liechtenstein, Lituânia, Luxemburgo, Madagascar, Mali, Malta, Mauritânia, Maurício, México, Moldávia, Mônaco, Mongólia, Namíbia, Nicarágua, Níger, Nigéria, Noruega, Países Baixos, Palau, Panamá, Paraguai, Peru, Portugal, Reino Unido, República Dominicana, República Checa, Romênia, Ruanda, Saint Kitts e Nevis, Samoa, Senegal, São Tomé e Príncipe, Seychelles, Serra Leoa, Singapura, Sri Lanka, Suriname, Suécia, Suíça, Síria, Tailândia, Togo, União Europeia, Uruguai, Vietnã, Zâmbia (MINAMATA CONVENTION, 2017).
} 
O sucesso, envolvendo uma negociação tão complexa, demanda um profundo estudo dos fatores que possibilitaram a sua efetivação. Os insights da abordagem teórica do realismo nas relações internacionais, em sua corrente neoclássica, fornecem um valioso aporte para tal análise.

\section{Interesses e constrangimentos internos e externos: contribuições do Realismo Neoclássico}

O realismo neoclássico surge no final dos anos de 1980 e se consolida como abordagem teórica relevante das relações internacionais durante os anos de 1990. Essa corrente se intitula "neo" clássica pois visa retomar dois aspectos analíticos do realismo clássico que foram negligenciados pelo realismo estrutural: o papel dos líderes políticos como variável analítica e a política externa como variável dependente (ROSE, 1998).

O exame do comportamento dos líderes políticos se enquadra naquela que é considerada a grande inovação teórica apresentada pelo realismo neoclássico: a incorporação das variáveis domésticas (intervenientes) para o estudo das políticas externas estatais (TALIAFERRO; LOBELL; RIPSMAN, 2009). Dessa forma, "no mundo do Realismo Neoclássico, os líderes podem ser constrangidos tanto por políticas internacionais quanto domésticas" (ROSE, 1998, p. 152, tradução livre7). Logo, a política externa dos Estados (variável dependente) constitui-se como o resultado da interação entre as pressões do sistema internacional (variável independente) e os condicionantes domésticos (variável interveniente) (KITCHEN, 2010).

As pressões internacionais devem ser compreendidas como o resultado das interações entre os Estados, tendo como balizador o poder relativo de cada um deles (SCHWELLER; PRIESS, 1997). Então, o poder relativo dos Estados se constitui como a principal variável independente (ROSE, 1998).

A respeito das variáveis intervenientes, não há um consenso entre os realistas neoclássicos a respeito de quais sejam as variáveis domésticas a serem investigadas. Todavia Taliaferro, Lobell e Ripsman (2009) apontam quatro fatores que, frequentemente, atuam como variáveis intervenientes: 1) capacidade governamental de mobilizar recursos; 2) influência de grupos de interesse; 3 )

7 No original em inglês: "In the neoclassical realist world leaders can be constrained by both international and domestic politics". 
grau de autonomia do Estado perante a sociedade; 4) nível de coesão da elite ou societal. Esses condicionantes domésticos e internacionais serão levados em conta pelos líderes políticos para implementar a sua agenda externa. Assim, as percepções dos líderes sobre o poder relativo de seus Estados e dos demais representam outra importante variável (ROSE, 1998). Portanto, são os líderes que definem os "interesses nacionais" e conduzem a política externa, baseados na sua leitura sobre o mundo (TALIAFERRO; LOBELL; RIPSMAN, 2009).

Esses entendimentos teóricos fornecem preciosos aportes para uma análise acerca dos constrangimentos que motivaram EUA e China a aderirem à Convenção de Minamata. O sucesso desse acordo multilateral global igualmente permite trazer ao debate acadêmico premissas tradicionais do realismo, como o pressuposto de que os Estados são os atores mais importantes do sistema internacional e a questão do papel central que as grandes potências exercem na política internacional.

Começando por esses dois pontos, importantes autores ressaltam que o êxito da Convenção de Minamata se relaciona, diretamente, com a postura de liderança nesse processo executada pela principal potência mundial, os EUA, e pela concordância da China, maior produtora do produto em escrutínio e também outra grande potência (ANDRESEN; ROSENDAL; SKJAERSETH, 2012; STOKES; GIANG; SELIN, 2016; SELIN, 2014; YANG, 2014).

Para Yang (2014), a rápida adesão de Washington ao acordo foi um passo crucial para garantir que a convenção tivesse um alcance efetivo com a participação de países chave. Mesmo antes da ratificação do tratado, durante o processo de negociação, quando os EUA anunciaram que estariam dispostos a aceitar uma abordagem juridicamente vinculativa em 2009, imediatamente vários países passaram a defender a mesma posição, incluindo Estados chave, como a China e a Índia (ANDRESEN; ROSENDAL; SKJAERSETH, 2012). Outrossim, conforme preconizava Yang (2004), o mais abrangente acordo ambiental global só seria eficiente se os principais Estados responsáveis pela poluição do mercúrio aderissem ao acordo, situação que realmente se materializou, com a adesão de Pequim e Nova Déli. Percebe-se assim que o pressuposto tradicional do realismo (também defendido pelos neoclássicos), de que os Estados são os atores mais importantes do sistema internacional, ainda encontra respaldo na realidade empírica (TALIAFERRO; LOBELL; RIPSMAN, 2009).

Além disso, o preceito do realismo neoclássico de que as decisões de política externa são tomadas pelos líderes, levando em conta os constrangimentos externos e internos aos quais são submetidos, parece ser um ótimo guia para a compreensão da 
adesão de Washington e Pequim à Convenção de Minamata (SCHWELLER; PRIESS; 1997). Iniciando pelo caso dos EUA, observa-se a existência de duas variáveis independentes: uma considerável perda de soft power na comunidade internacional, em razão de políticas unilaterais do governo W. Bush, e a possibilidade de existir uma maior regulação internacional sobre as emissões atmosféricas de mercúrio. Segundo o postulado do realismo neoclássico, para compreender como os Estados interpretam e respondem às pressões sistêmicas, é necessário analisar como as mesmas se traduzem em variáveis intervenientes domésticas (ROSE, 1998).

A primeira variável independente irá se relacionar com a mudança de orientação político-ideológica da presidência dos EUA (W. Bush - Obama). Durante o governo do primeiro, Washington defendia um entendimento voluntário para tratar do problema do mercúrio. Com a chegada de Obama ao poder, essa abordagem alterou-se profundamente (ANDRESEN; ROSENDAL; SKJAERSETH, 2012). Também pode-se agregar à análise outro elemento relevante para o realismo neoclássico: a personalidade e a percepção dos líderes sobre a realidade material (TALIAFERRO; LOBELL; RIPSMAN, 2009). Nessa linha, destaca-se que Obama possuía um interesse pessoal sobre o assunto, visto que, quando ele ainda era senador em 2007, introduziu uma lei que proíbe a venda, distribuição, transferência e exportação de mercúrio (ANDRESEN; ROSENDAL; SKJAERSETH, 2012). Na ocasião da promulgação da lei, Obama comentou:

A aprovação pelo presidente desse projeto de lei bipartidário é uma importante vitória para milhões de cidadãos vulneráveis do mundo que estão expostos aos efeitos nocivos do mercúrio todos os dias. A exposição ao mercúrio leva a sérios problemas de desenvolvimento em crianças, bem como a problemas que afetam a visão, habilidades motoras, pressão arterial e fertilidade em adultos. Apesar dos esforços do nosso país para conter e coletar mercúrio ao longo dos anos, continuamos sendo um dos líderes mundiais na exportação desse perigoso produto, por isso estou orgulhoso que esse projeto de lei irá finalmente proibir as exportações de mercúrio. (UNITED STATES, 2008, p. 1, grifos nossos, tradução livre ${ }^{8}$ )

8 No original em inglês: "The President's approval of this bipartisan bill is an important victory for millions of the world's most vulnerable citizens who are exposed to the harmful effects of mercury every day," Senator Obama. "Exposure to mercury leads to serious developmental problems in children as well as problems affecting vision, motor skills, blood pressure, and fertility in adults. Despite our country's improved efforts to contain and collect mercury over the years, we remain one of the world's leading exporters of this dangerous product, so I am proud this bill will finally ban mercury exports”. 
Ao interesse pessoal do líder, conjuga-se a necessidade de melhora do soft power americano (variável independente). Essa mudança de comportamento também pode ser vista no esforço de Obama em fortalecer o multilateralismo dos EUA, visando recuperar o prestígio do país. O discurso de estreia de Obama nos encontros anuais da Assembleia Geral das Nações Unidas em 2009 exemplifica essa postura:

Eu assumi o cargo em uma época em que muitos ao redor do mundo viam a América com ceticismo e desconfiança. Parte disso foi devido a percepções errôneas e desinformação sobre o meu país. Parte disso se deve à oposição a políticas específicas e à crença de que, em certas questões críticas, os Estados Unidos agiram unilateralmente, sem considerar os interesses de outros. Isso alimentou um antiamericanismo quase que automático, que muitas vezes serviu como uma desculpa para nossa inação coletiva (...) Mas acredito firmemente que no ano de 2009 - mais do que em qualquer outro momento da história da humanidade - os interesses das nações e dos povos são compartilhados (...) Devemos abraçar uma nova era de engajamento baseada em interesses mútuos e respeito mútuo, e nosso trabalho deve começar agora (...) Em uma era em que nosso destino é compartilhado, o poder não é mais um jogo de soma zero. Nenhuma nação pode ou deve tentar dominar outra nação. Nenhuma ordem mundial que eleva uma nação ou grupo de pessoas sobre outra terá sucesso. (OBAMA, 2009, p. 1-3, grifos nossos, tradução livre' ${ }^{9}$.

Essa declaração denota uma articulação entre a variável interveniente (percepção do líder) com a variável independente (antiamericanismo). Dessa forma, houve um cenário propício ao retorno de Washington ao multilateralismo. Nesse contexto, cabe registrar que o último grande tratado multilateral, no âmbito do meio ambiente, assinado pelos EUA, foi a Convenção das Nações Unidas para o Combate da Desertificação, no distante ano de 1994 (YANG, 2014).

9 No original em inglês: "I took office at a time when many around the world had come to view America with skepticism and distrust. Part of this was due to misperceptions and misinformation about my country. Part of this was due to opposition to specific policies, and a belief that on certain critical issues, America has acted unilaterally, without regard for the interests of others. This has fed an almost reflexive anti-Americanism, which too often has served as an excuse for our collective inaction (...) But it is my deeply held belief that in the year 2009 - more than at any point in human history - the interests of nations and peoples are shared (...) We must embrace a new era of engagement based on mutual interests and mutual respect, and our work must begin now (...) In an era when our destiny is shared, power is no longer a zero sum game. No one nation can or should try to dominate another nation. No world order that elevates one nation or group of people over another will succeed". 
Já a outra variável independente conecta-se com a conveniência de dispor de maior ingerência sobre as emissões de mercúrio na atmosfera, as quais têm um impacto direto nos EUA. Segundo Andresen, Rosendal e Sjkjoerseth (2012), somente $17 \%$ do mercúrio depositado em solo americano advém do país ou do Canadá. Visto que a China é o principal exportador de emissões de mercúrio para os EUA, Washington tem um grande interesse em uma efetiva regulação internacional das emissões de mercúrio (ANDRESEN; ROSENDAL; SKJAERSETH, 2012). Essa aspiração externa conjuga-se com as pressões domésticas sob o uso do mercúrio. Selin (2014) aponta que, em 2011, os EUA passaram a estipular padrões mais rigorosos para emissões de mercúrio em usinas de energia. Portanto, a visão realista neoclássica, de que os líderes enfrentam um jogo de dois níveis (interno e externo) para implementar a sua agenda externa, parece se aplicar bem no caso em questão (TALIAFERRO; LOBELL; RIPSMAN, 2009).

Analisando a ratificação chinesa à Convenção de Minamata por tal perspectiva teórica, pondera-se que, como variável independente, está a pressão em participar desse regime internacional, em razão de Pequim ser o maior produtor de mercúrio. Conjunturalmente, o fato de os EUA terem, a partir de 2009, concordado com uma abordagem, juridicamente, vinculativa sobre a temática do mercúrio, possivelmente constrangeu a China a aderir a essa posição, em razão do custo político (ANDRESEN; ROSENDAL; SKJAERSETH, 2012). Isso posto, convém trazer a visão realista neoclássica, a qual reconhece a importância de pressões externas competitivas e os efeitos socializantes que moldam o comportamento dos Estados. Porém, postula-se que a motivação dos Estados advém não do apelo normativos dos outros Estados, mas sim do desejo de aumentar a sua vantagem competitiva e sua chance de sobrevivência (TALIAFERRO; LOBELL; RIPSMAN, 2009). Também se destaca que a estratégia de consentir com regimes internacionais compulsórios oferece às potências emergentes um "assento à mesa" para informar as suas demandas, dando-lhes oportunidade para que tenham uma voz efetiva (SCHWELLER; PRIESS, 1997).

O constrangimento gerado pela variável independente, descrita acima, irá se conectar com um ambiente doméstico político-econômico extremamente favorável à limitação do uso do mercúrio. O realismo neoclássico identifica a capacidade estatal em extrair recursos e mobilizar sua sociedade como uma crucial variável interveniente entre imperativos sistêmicos e a formulação e execução da política externa (TALIAFERRO; LOBELL; RIPSMAN, 2009). Dessa forma, destaca-se que, nos últimos anos, o uso limitado do mercúrio resultou no avanço na utilização de 
outros materiais como fonte de energia (ANDRESEN; ROSENDAL; SKJAERSETH, 2012). Na China, em 2013, o uso de fontes não carvoeiras superou as de carvão, sinalizando uma mudança do uso da eletricidade baseada em carvão (CEC, 2013). A limitação e o uso mais eficiente e sustentável do mercúrio pela China têm sido possível na medida em que Pequim dispõe da tecnologia necessária para tanto. Ademais, o país possui importantes recursos potenciais de xisto (STOKES; GIANG; SELIN, 2016).

Afora esses condicionantes econômicos, outro fator tem exercido pressão sob o setor de mercúrio e o governo chinês: a poluição do ar tornou-se uma importante questão política na China, com as emissões de carvão ocupando um relevante papel nesse sentido (STOKES; GIANG; SELIN, 2016). A população chinesa tem estado cada vez mais insatisfeita com a regulamentação do governo a respeito das usinas de energia (ZHENG; KAHN, 2013). Dessa forma, Pequim começou a tomar medidas mais rigorosas a respeito da qualidade do ar (STOKES; GIANG; SELIN, 2016).

Tal associação entre variáveis independentes e intervenientes é fundamental para entender a decisão de Pequim de aderir à Convenção de Minamata. Também é útil o entendimento realista neoclássico de que são os líderes políticos que definem o "interesse nacional"; no caso chinês, fica claro que esse também se confunde com o interesse de manutenção do status quo político da elite. Assim, ao participar do regime em questão, a elite política chinesa não apenas visa elevar a sua legitimidade doméstica (variável interveniente), como também aumentar sua capacidade de impor sua agenda e influenciar em decisões internacionais acerca de um tema tão caro a si (variável independente).

Exposto esses condicionantes internos e externos ao processo de adesão de EUA e China à Convenção de Minamata, e partindo para uma análise mais extensiva desse regime, acredita-se que o realismo neoclássico possa lançar luz em alguns pontos relevantes. Não parece exagerado dizer que parte importante do sucesso da entrada em vigor da Convenção de Minamata se deve à não oposição daqueles que são, atualmente, os dois mais poderosos Estados do sistema internacional: EUA e China. É muito representativo o fato de Washington ter sido o primeiro Estado a assinar e ratificar a convenção, e a China, maior produtora mundial de mercúrio, também ter demonstrado a sua concordância com o acordo.

Retomando a visão clássica de Morgenthau (2003), há a compreensão de que as normas do direito internacional ocorrem em razão de dois fatores: os interesses comuns ou complementares dos Estados e a distribuição entre eles. Schweller e 
Priess (1997) vão ainda mais longe ao pontuar que os regimes internacionais têm como origem um conluio entre os Estados mais poderosos a fim de atender aos seus interesses e à custa dos demais Estados (SCHWELLER; PRIESS, 1997). Talvez em nosso objeto não tenha havido um conluio, mas sim, conforme expôs Morgenthau (2003), uma complementaridade de interesses de duas grandes potências.

Uma vez dentro desses arranjos internacionais, as grandes potências possuem a legitimidade do direito para justificarem a imposição dos seus interesses. Para Mansfield (1995), os Estados possuem incentivos para utilizar as instituições internacionais porque elas podem representar uma fonte de poder para quem as controla. O autor continua afirmando que "os atores que ganham poder por meio de uma instituição têm a habilidade de impor a sua agenda e influenciar a distribuição dos benefícios e custos entre os membros" (MASFIELD, 1995, p. 600, tradução livre10).

De modo complementar, para Carr (2001), as instituições e o direito internacional são associados com a política do status quo, o legítimo direito das potências dominantes de imporem as "regras do jogo", procurando manter o seu poder relativo e seus interesses. Na mesma linha, Gilpin (1981) coloca que, embora as regras que governem o comportamento estatal variem, a principal fonte de criação dessas regras são a conjunção entre o poder e os interesses das grandes potências. No caso da Convenção de Minamata, os interesses convergentes de grandes potências como EUA e China parecem ter sido a razão principal para a efetivação desse regime internacional.

\section{Construtivismo}

Há três caminhos, apontados por Goldstein e Keohane (1993), pelos quais as ideias têm o potencial de influenciar os resultados das políticas. A primeira via deriva da necessidade dos indivíduos de determinar suas próprias metas e estratégias alternativas de política para atingir objetivos. As ideias se tornam importantes quando os atores acreditam nas ligações causais que eles, quando atores reconhecem ou nos princípios normativos que eles representam. Desse modo, ideias são como road maps. Esse caminho não considera que as ideias são válidas

10 No original em inglês: "Actors that gain power within an institution have the ability to set its agenda and influence the distribution of benefits and costs among members". 
e persuasivas, mas, uma vez que uma ideia é selecionada, esse caminho limita a escolha porque, logicamente, exclui outras interpretações da realidade ou, pelo menos, sugere que tais interpretações não são dignas de exploração sustentada.

O segundo caminho - focal points - afirma que as ideias afetam as interações estratégicas, ajudando ou dificultando esforços conjuntos para atingir o resultado mais eficiente (os resultados que são, pelo menos, tão bons quanto o status quo para todos os participantes). Nesse ponto, as ideias contribuem para resultados na ausência de um único equilíbrio. Podem servir como focal points que definem soluções cooperativas ou agir como “cola” de coalizão a fim de facilitar a coesão de grupos específicos - que podem até mesmo impedir um acordo sobre uma base mais ampla.

No terceiro caminho - a institucionalização - as ideias se tornam incorporadas nas regras e normas - isto é, uma vez que elas se tornem institucionalizadas - restringindo as políticas públicas. Goldstein e Keohane (1993) afirmam que as políticas são influenciadas, primeiramente, pelas road maps, ou por algum acordo passado (focal points), ou pela existência de algum padrão de coalizão em detrimento de outro. Em suma, as ideias incorporadas nas instituições especificam as políticas na ausência de uma inovação. Os autores afirmam que uma análise pelo caminho institucional não diz nada a respeito sobre o porquê de as ideias terem sido inicialmente estabelecidas.

Judith Goldstein e Robert Keohane (1993) fazem uma observação e uma crítica sobre a categorização das ideias e o modo como se deve analisar o papel das ideias nas ações políticas. Segundo os autores, a categorização das ideias é clara no plano abstrato. Na vida social, os três caminhos das ideias devem ser analisados juntos. O erro mais comum que os defensores do papel das ideias têm feito é assumir uma relação causal entre as ideias dos formuladores de políticas e as opções políticas. As ideias estão sempre presentes nos debates sobre políticas, uma vez que são uma condição para o discurso fundamentado. Mas, se muitas ideias estão disponíveis para uso, os analistas não devem assumir que a propriedade intrínseca de uma ideia explique sua escolha por parte dos decisores políticos. As escolhas de ideias específicas podem, simplesmente, refletir os interesses dos atores. É fundamental, para quem trabalha com ideias e política, reconhecer que a definição da existência de determinadas crenças não é nenhum substituto para o estabelecimento de seus efeitos sobre a política (GOLDSTEIN; KEOHANE, 1993).

Um modelo de análise de política externa que contempla um aspecto amplo, incorporando fatores domésticos, internacionais e organizacionais da sociedade, 
contemplando aspectos racionalistas e reflexivistas, encontra eco no trabalho do ex-ministro das Relações Exteriores da Argentina Héctor Eduardo Gosende (2007). Ele classifica a política externa em três categorias: interesses, objetivos e instrumentos. Segundo o autor, através da política externa se promovem valores, tanto materiais como não materiais. Ao se supor que os atores são movidos em função de seus interesses, a explicação de que tipo de valores interfere na decisão aumenta a capacidade de predição do analista e a coerência do próprio decisor. $\mathrm{O}$ conceito de objetivo se sujeita ao interesse. $\mathrm{O}$ objetivo se refere a um fim imediato, enquanto o interesse é um fim mediado que guia a escolha do tomador de decisão. Concretamente, o objetivo da política externa se refere ao resultado buscado ou a que se pretende chegar em relação a outro Estado ou a grupos pertencentes a esse outro Estado. Por sua vez, o instrumento está a serviço do objetivo e consiste em uma série de medidas ou utilizações de práticas internacionais por atores, que serve para implementar as políticas exteriores.

Gosende (2007) também afirma a existência de variáveis que influenciam as tomadas de decisões. Podem-se classificar as influências em três categorias: a) aquelas que emanam da sociedade; b) aquelas que surgem dos eventos internacionais (meio externo); c) aquelas que são produtos das organizações governamentais e que são parte do processo de decisão.

Os esquemas teóricos sobre o estudo de política externa, utilizando-se de variáveis internas e externas, levam à conclusão de que existe uma interação entre o impacto das políticas internacionais e as estruturas domésticas. Ambas se afetam mutuamente. Para tanto, ao se considerar os fatores internacionais que influenciam a política externa de um país, Gosende (2007) classifica-as em três tipos: a) as referidas ao poder entre os Estados; b) as que se referem à economia; c) as ideias ou ideologias que penetram no Estado.

Em relação aos fatores internos, Gosende (2007) apresenta as seguintes observações: a) deve-se analisar o tipo de regime em que o Estado está inserido; b) o padrão de coalizões - tipo e composição das elites governantes e o modo como negociam entre si e com o estrangeiro e; c) as ideias, crenças e ideologias dos distintos grupos que disputam o poder e a decisão em matéria de política externa.

Portanto, o modelo de análise de política externa pode ser ilustrado no quadro abaixo (Quadro 1): 


\section{Quadro 1 - Modelo Teórico}

\begin{tabular}{|l|l|l|}
\hline \multicolumn{3}{|c|}{ Modelo Teórico } \\
\hline Fatores Externos & Organização da Sociedade & Fatores Internos \\
\hline Referidos ao poder entre os Estados & Organização do Estado & Tipo de regime \\
\hline Referidos à Economia & Organização da Sociedade & Padrão de coalizões \\
\hline Referidos a ideias e ideologias & $\begin{array}{l}\text { Características básicas do } \\
\text { processo de desenvolvimento }\end{array}$ & Cultura política e ideológica \\
\hline
\end{tabular}

Fonte: elaborado pelos autores a partir de Gosende, 2007.

Esse modelo tenta descrever o conjunto de ideias consistentes e relacionadas entre si que se convertem no mapa cognitivo de um decisor político. O modelo tenta refletir de forma simplificada o "modelo da situação" que os tomadores de decisão têm em mente quando tomam alguma decisão. O esquema desenvolvido representa a inter-relação de variáveis internas e externas do sistema político e os tipos de prioridades, interesses, objetivos e ferramentas usadas para produzir as decisões buscadas.

Dessa forma, algumas variáveis importantes são caras para o modelo analítico proposto acima. Em primeiro lugar, os fatores subjetivos - ideias, crenças e valores - importam e precisam ser levados em consideração. No que tange à Convenção de Minamata, a figura do presidente, centralizador do processo decisório tanto nos Estados Unidos quanto na China, foi fundamental. Como exposto previamente, a questão do mercúrio era cara ao presidente Barack Obama, o que tornou não só a adesão, mas o incentivo a outros países a participarem da convenção, como algo importante em sua visão de mundo. Da mesma forma, a China vem agregando a agenda do meio ambiente em seus valores políticos, o que se reflete nos discursos de seus principais líderes ${ }^{11}$, e adotando uma maior participação nos regimes internacionais que tratam desse assunto. O discurso do então chanceler chinês Yang Jiechi na $66^{\circ}$ Sessão da Assembleia Geral da ONU em 2011 ilustra o ponto:

Houve progresso na reforma da estrutura de governança econômica global e vários mecanismos de cooperação regional estão se expandindo. Esforços para acelerar o desenvolvimento de uma economia verde e explorar novos modos de crescimento sustentável criaram um novo impulso e espaço para o desenvolvimento comum. Diante de novas oportunidades e desafios,

11 De acordo com a Bloomberg (2017), a menção à proteção do meio ambiente nos discursos dos presidentes chineses durante os encontros quinquenais do partido comunista chinês vem crescendo progressivamente. No último congresso (2017), pela primeira vez o termo "meio ambiente” foi mais citado que "economia". 
devemos trabalhar em equipe para superar nossas dificuldades e buscar benefícios mútuos e desenvolvimento comum (...) 0 mundo irá ver uma China mais aberta, com desenvolvimento mais sustentável e com maior harmonia social. (JIECHI, 2014, pp. 41-44, grifos nossos, tradução livre'12)

Por último, os fatores externos determinam o comportamento dos agentes. Não se discutem os malefícios causados pelo mercúrio. No entanto, ele é um efeito colateral de alguns processos comerciais, como, por exemplo, da mineração. A criação de uma agenda política internacional para discutir como lidar e impor regras sobre a utilização ou destinação do mercúrio é o que moveu os agentes a criar um regime internacional sobre tal tema.

A institucionalização ocorre motivada por um fator interno e doméstico ocorrido no Japão, um dos países mais desenvolvidos do mundo. A comoção causada pelos efeitos do mercúrio na sociedade japonesa influenciou na decisão de se criar um regramento sobre o tema. Logo, dado o sucesso na criação e na participação de importantes players globais, as regras e o regime criados a partir da convenção foram, amplamente, aceitas pelos países. A normatização do sistema internacional produz a socialização a partir do relacionamento entre os agentes.

A socialização pode ser definida como um processo de indução de atores para as normas e regras de uma determinada comunidade. Seu resultado é sustentado em conformidade na internalização de novas normas. Na adoção de regras comunitárias, a socialização implica mudança comportamental do agente: de uma lógica de consequências para uma lógica de adequação ${ }^{13}$. Essa adoção é sustentada ao longo do tempo e é bastante independente de uma estrutura específica de incentivos materiais ou sanções (CHECKEL, 2005).

Se o objetivo é teorizar os processos de socialização, no entanto, também precisamos questionar quando e como ocorre uma mudança para a internalização. O “quando" exige que se distinga entre situações em que a mudança resulta de uma socialização e de situações induzidas somente por um cálculo de custos e benefícios - quando os atores mudam de uma lógica de consequências para uma

12 No original em inglês: "Progress has been made in the reform of the global economic governance structure, and various regional cooperation mechanisms are expanding. Efforts to accelerate the development of a green economy and explore new modes of sustainable growth have created new momentum and space for common development. Faced with new opportunities and challenges, we should work as a team to overcome our difficulties and pursue mutual benefit and common development (...) The world will see a more open China, with more sustainable development and greater social harmony".

13 Os custos da lógica de adequação, isto é, incorporar as normas e se inserir no regime internacional, são menores do que os custos de não participar, evitando constrangimentos e punições. 
lógica de adequação. Sobre o "como", é preciso pensar em mecanismos, como estes três destacados: cálculo estratégico, role playing e persuasão normativa. Por sua vez, esses sugerem três modelos de racionalidade que podem contribuir para a socialização: instrumental, limitado e comunicativo (CHECKEL, 2005).

Existem dois tipos diferentes de socialização: No primeiro, os agentes podem se comportar de forma adequada, aprendendo um papel - aquisição de conhecimento que lhes permite agir de acordo com as expectativas - independentemente de aceitar o papel ou concordar com ele. A chave são os atores saberem o que é socialmente aceito em um determinado ambiente ou comunidade. Já o segundo tipo de socialização segue uma lógica de adequação. Isto significa que o cálculo instrumental consciente foi substituído por role playing consciente. Esta lógica de adequação pode ir além de role playing e implica que os agentes aceitem as normas da comunidade ou de uma organização como "a coisa certa a fazer". Um dos resultados desse Tipo II de socialização são os agentes adotarem os interesses - até mesmo a identidade - da comunidade de que eles estão separados. (CHECKEL, 2005).

Em suma, se verificado o cálculo estratégico operado sozinho, é possível que não haja socialização e internalização. Não há uma mudança de uma lógica de consequências para uma lógica de adequação, sendo os atores vistos como instrumentalmente racionais. Nesse caso, a ênfase está na importância da condicionalidade política no processo de socialização. Definida como o uso de incentivos materiais para provocar uma mudança desejada no comportamento de um Estado alvo, a condicionalidade é a política baseada em incentivos por excelência (CHECKEL, 2005).

Já o role playing é um mecanismo de socialização que tem raízes nas teorias de organizações e na psicologia cognitiva. Agentes são vistos como, limitadamente, racionais. Não é possível para eles assistirem a tudo ao mesmo tempo ou calcular cuidadosamente os custos e benefícios de cursos alternativos de ação; atenção é um recurso escasso. Ambientes organizacionais ou de grupo fornecem atalhos simplificadores, sugestões e buffers que podem levar à promulgação ou a particulares concepções do papel - role playing - entre os indivíduos (CHECKEL, 2005). Quando o role playing ocorre, a alteração de uma lógica de consequências para uma lógica de adequação começa e envolve uma adaptação não calculável de comportamento.

Por fim, e lembrando que role playing pressupõe um agente passivo à aceitação de novos papéis, evocados por certos gatilhos ambientais, quando a persuasão 
normativa ocorre, os agentes de forma ativa e reflexiva internalizam novos entendimentos de adequação. Se perguntado sobre a origem da conformidade, os agentes podem responder: "Bem, esta é a coisa certa a fazer, mesmo que eu não costumasse pensar assim” A mudança de uma lógica de consequências para uma lógica de adequação está completa, e o resultado é o tipo II de internalização (CHECKEL, 2005, p. 812). Essa é, portanto, a persuasão normativa. Ela ocorre quando o conjunto de regras é internalizada e aceita pelos agentes. Não obstante, como afirmado por Onuf (1998), as regras são um dos componentes mais importantes das relações sociais, uma vez que elas servem tanto para dizer como um agente deve se comportar, quanto para dizer como ele deve atuar.

Nesse contexto, é muito importante o papel do "socializador”. Esse agente é o principal fator de indução para que outros Estados ingressem no mecanismo de socialização. Em outras palavras, o socializador serve como um norte para os demais envolvidos, isto é, se ele faz parte desse mecanismo, logo esse deve ser uma boa coisa para todos. A Convenção de Minamata, portanto, ao contar com a participação dos Estados Unidos e da China, faz com que as chances de institucionalização do caso do mercúrio e do processo de socialização sejam altas. Primeiramente, pelo fato de os dois países compartilharem um conjunto de valores e de visão de mundo que são compartilhados pelos outros Estados. Dessa forma, haveria uma certa tendência a segui-los. Segundo, o sentimento de que "essa é a coisa certa a fazer" - a lógica de adequação - se tornaria mais acessível pelo fato das maiores potências se comprometerem a seguir tais regras.

Por fim, ao se ratificar internamente a Convenção de Minamata, os socializadores não apenas servem como exemplo, mas passam também - se essa for uma questão cara para eles - a exercer a coerção normativa. A partir do momento em que o regime e a institucionalização saem do campo ideal e rumam para a prática, o comportamento dos Estados passa a ser determinado pela adoção coletiva desse regramento. Haverá a distinção entre os que estão na regra do jogo e os que estão fora. Esse primeiro grupo de países tende a ser recompensado - mesmo que apenas como benquistos pela opinião pública internacional - enquanto o segundo tende a ser marginalizado pelo comportamento de não aderir a uma convenção amplamente aceita e que é vista com bons olhos.

Dificilmente haveria uma única forma analítica de responder às questões do que causou o aparente sucesso da Convenção de Minamata ou o porquê da adesão de grandes potências globais. Por um lado, poderia ser um jogo de interesses políticos e comerciais, imposição de uma agenda ou uma forma de exercer poder 
através da criação e adesão de regimes. Por outro lado, os interesses em criar e participar de uma institucionalização também podem ser gerados a partir de ideias, valores e crenças sobre o que seria o certo a fazer. Além disso, o caminho não seria o uso da força, mas a via negociada multilateralmente. Sem descartar o papel dos interesses e da persuasão, o construtivismo contribui para a análise a partir da percepção de que vários outros fatores influenciam a decisão de um Estado ou de um líder. Assim, as normas, regras e regimes adotados e aceitos amplamente possuem tanto o papel de coerção como também desempenham a função de criar ou aprofundar as interações entre os agentes internacionais. Por fim, uma perspectiva de interlocução teórica favorece a constatação de que o debate sobre a socialização contempla pressupostos que poderiam ser classificados como associados ao realismo. Contribuindo para que o campo das relações internacionais desempenhe cada vez mais um debate interparadigmático entre as diversas correntes teóricas.

\section{Conclusão: um diálogo entre Realismo Neoclássico e Construtivismo em Global Environmental Politics}

O esforço em estabelecer pontes entre o realismo neoclássico e o construtivismo vem ocorrendo no debate teórico das relações internacionais, ainda que timidamente (ROSE, 1998; STERLING-FOLKER, 2002; JACKSON; NEXON, 2002; KITCHEN, 2010). Segundo Sterling-Folker (2002), o realismo neoclássico é capaz de incorporar premissas do realismo estrutural, como a influência de atores externos, com insights construtivistas, como as dinâmicas e pressões da identidade coletiva nacional. Similarmente, para Rose (1998), os realistas neoclássicos ocupam uma via média entre as teorias estruturais e os construtivistas. Eles assumem que existe, sim, uma realidade material, porém essa não é clara e objetiva, estando dependente da leitura feita pelos líderes. Porém, a tentativa de relacionar tal aproximação com a agenda de Global Environmental Politics ainda é muito incipiente na academia. Nesse sentido, esta subseção final visa tentar preencher essa lacuna.

Partindo do pressuposto de que o sucesso da Convenção de Minamata é fruto da adesão de China e EUA, é necessário empreender uma investigação dos fatores que levaram a essa situação. Todavia uma investigação mais sólida a respeito desses condicionantes demanda levar em conta os constrangimentos internos e externos à Pequim e Washington. Igualmente, tal análise não pode 
deixar de evidenciar as variáveis materiais e não materiais do processo. Tendo esse quadro, é possível delinear alguns apontamentos iniciais sobre um diálogo entre as abordagens realista neoclássica e construtivista.

Uma das grandes contribuições de ambas teorias e um importante ponto de aproximação entre elas consiste na consideração das variáveis internas e externas para a análise de política externa. Esse entendimento representa um avanço diante da visão estrutural do realismo, que ignora esses condicionantes domésticos. Contudo, a ênfase e a seleção dessas variáveis internas revela matrizes epistemológicas distintas (ainda que não conflitantes): os primeiros focam nos aspectos materiais e os segundos nos ideacionais. Cabe destacar que essa ênfase não significa exclusão: para o realismo neoclássico, a realidade material se traduz através da percepção dos líderes políticos, esses influenciados por crenças e ideias (TALIAFERRO; LOBELL; RIPSMAN, 2009); para os construtivistas, as políticas são influenciadas por interesses e ideias (KEOHANE; GOLDSTEIN, 1993).

Assim, retornando ao caso da Convenção de Minamata, nota-se que os insights realistas neoclássicos podem ser combinados com um olhar construtivista. Os primeiros concebem que a política internacional e o multilateralismo são dominados pelas grandes potências (EUA e China, por exemplo), que empregam as normas internacionais para legitimar os seus interesses. Agregando a visão construtivista, a análise pode ser complementada com o conceito de socialização das normas, no qual os atores buscam aderir a determinados ordenamentos jurídicos de modo a não serem excluídos. Esse também parece ser o caso dos EUA e China em relação à Convenção de Minamata, na medida em que a agenda de meio ambiente desperta cada vez mais a atenção e gera contínuos constrangimentos aos Estados que não a adotam.

Por fim, a participação na Convenção de Minamata pode ser o reflexo dos interesses dos Estados em aderir a um regime internacional de aparente sucesso e com aceitação da opinião pública. Com isso, diminuiriam seus custos por não participarem e se manterem marginais a um regime internacional. Por outro lado, não se pode excluir a possibilidade de tal participação como um processo de socialização que existiria a partir da institucionalização da convenção. Em um primeiro momento, a negociação da adesão pode ser um reflexo de cálculo de custos e benefícios. Porém, a partir do momento em que se atinge a compreensão de que regrar a utilização do mercúrio é “o certo a se fazer”, a lógica deixa de ser de custos e benefícios e passa a ter que ver com o compartilhamento desse espírito de "coisa certa a se fazer" - ou seja, estamos no campo da socialização. 
Assim, os pressupostos do realismo neoclássico e do construtivismo podem ser amplamente utilizados para explicar o sucesso de Minamata, mostrando que é possível a criação de um diálogo entre as duas teorias de relações internacionais.

\section{Referências}

ANDRESEN, Steinar; ROSENDAL, Kristin; SKJAERSETH, Birger. Why Negotiate a Legally Binding Mercury Convention? International Environmental Agreements: Politics, Law and Economics, v. 13, n. 4, 2012, p. 425-440.

BLOOMBERG. Xi's Speech Had 89 Mentions of the 'Environment,' Just 70 of the 'Economy'. Bloomberg.com. 18 Out. 2017. Disponível em: < https://www.bloomberg.com/news/ articles/2017-10-18/in-xi-s-vision-for-china-environment-edges-out-economy $>$. Acesso: 16/10/2018.

CARR, Edward. Vinte Anos de Crise: 1919-1939. São Paulo: Editora Universidade de Brasília, 2001.

CHECKEL, Jeffrey. International Institutions and Socialization in Europe: Introduction and Framework. International Organization, Cambridge, v. 50, n. 4, 2005, p. 801-826.

COMISSÃO EUROPEIA. Press Realease Database. Apresenta informações sobre a política da União Europeia para a Convenção de Minamata. Disponível em: < http://europa. eu/rapid/press-release_MEMO-17-1344_en.htm > . Acesso em: 24/07/2017.

CHINA. Conselho de Eletricidade da China (CEC). CEC Publishes the Demand/Supply Analysis and Forecast of China Power Industry. Beijing: China Electricity Council, 2013. ERIKSEN, Henrik; PERREZ, Franz. The Minamata Convention: A Comprehensive Response to a Global Problem. RECIEL - Review of European Community \& International Environmental Law, v. 23, n. 2, 2014, p. 195-210.

GILPIN, Robert. War and Change in World Politics. New York: Cambridge University Press, 1981.

GOLDSTEIN, Judith; KEOHANE, Robert. Ideas and Foreign Policy. Ithaca: Cornell University Press, 1993.

GOSENDE, Héctor. Modelos de política exterior argentina: alternativas para salir del modelo conservador-menemista. Buenos Aires: Libros de Tierra Firme, 2007.

JACKSON, Patrick; NEXON, Daniel. Globalization, the Comparative Method, and Comparing Constructions. In. GREEN, Daniel. Constructivism and Comparative Politics. Armonk, NY: M.E. Sharpe, 2002, p. 88-120.

KITCHEN, Nicholas. Systemic pressures and domestic ideas a neoclassical realist model of grand strategy formation. Review of international studies, v. 36, n. 1, 2010, p. 117-143. 
MANSFIELD, Edward. International Institutions and Economic Sanctions. World Politics, v. 4, n. 7, 1995, p. 575-605.

MINAMATA CONVENTION on Mercury. Apresenta informações sobre a Convenção de Minamata. 24-29 Setembro de 2017. Disponível em: < http://cop1.mercuryconvention. org/events-on-the-side/mia-clinics/ > . Acesso em 22/09/2017.

JIECHI, Yang. Minister Yang Adress To The 66th Session Of The Un General Assembly. 26 de Setembro de 2011. Disponível em: < http://www.un.org/ga/search/view_doc. asp? symbol = A/66/PV.25 > . Acesso em 20/09/2018.

MORGENTHAU, Hans. A Política entre as Nações: a Luta pelo Poder e pela Paz. São Paulo: Editora Universidade de Brasília, 2003.

OBAMA, Barack. Remarks of President Barack Obama - As Prepared for Delivery "Responsibility for our Common Future" Address to the United Nations General Assembly. 23 de Set. 2009. Disponível em: < https://gadebate.un.org/sites/default/ files/gastatements/64/64_US_en.pdf > . Acesso: 16/10/2018.

ONUF, Nicholas. “Constructivism: a User's Manual”. In: International Relations in a Constructed World, editado por KUBÁLKOVÁ; ONUF; KOWERT, London /Armonk, NY, Me Shape, p. 58-78, 1998.

ROSE, Gideon. Neoclassical Realism and Theories of Foreign Policy. World Politics, v. 51, n. 1, 1998, p. 144-72.

SCHWELLER, Randall; PRIESS, David. A Tale of Two Realisms: Expanding the Institutions Debate. Mershon International Studies Review, v. 41, n. 1, 1997, p. 1-32.

SELIN, Henrik. Global Environmental Law and Treaty-Making on Hazardous Substances: The Minamata Convention and Mercury Abatement. Global Environmental Politics, V. 14, n. 1, 2014, p. 1-19.

STERLING-FOLKER, Jennifer. Realism and the Constructivist Challenge: Rejecting, Reconstructing or Rereading. International Studies Review, 4, 2002, p. 73-97.

STOKES, Leah; GIANG, Amanda; SELIN, Noelle. Splitting the South: China and India's Divergence in International Environmental Negotiations. Global Environmental Politics, v. 16, n. 4, 2016, p. 12-31.

TALIAFERRO, Jeffrey; LOBELL, Steven; RIPSMAN, Norrin. Introduction. In: TALIAFERRO, Jeffrey; LOBELL, Steven; RIPSMAN, Norrin (Eds). Neoclassical Realism, the State, and Foreign Policy. Cambridge: Cambridge University Press, 2009, p. 1-41.

UNITED NATIONS ENVIRONMENT PROGRAMME (UNEP). Proceedings of the Governing Council/Global Environment Ministerial Forum at its Twenty-Second Session. 3 - 7 Fev. 2003. Disponível em: < http://wedocs.unep.org/bitstream/handle/20.500.11822/10645/ K0360655-E-GC22_Proceeding.pdf? sequence $=1$ \&isAllowed $=y>$. Acesso: 16/10/2018 UNITED NATIONS ENVIRONMENT PROGRAMME (UNEP). Proceedings of the Governing Council/Global Environment Ministerial Forum at its Twenty-Third Session. 21 - 25 
Fev. 2005. Disponível em: < http://www.cep.unep.org/pubs/meetingreports/LBS \% 20 ISTAC \% 20III/english/UNEP\% 20GC23 \% 20Proceedings.doc > . Acesso: 16/10/2018

UNITED NATIONS ENVIRONMENT PROGRAMME (UNEP). Proceedings of the Governing Council/Global Environment Ministerial Forum at its Twenty-Fourth Session. 5-9 Fev. 2007. Disponível em: < https://wedocs.unep.org/bitstream/handle/20. 500.11822/10624/K0760630_GC24-proceedings.pdf? sequence $=1$ \&isAllowed $=y>$. Acesso: 16/10/2018

UNITED NATIONS ENVIRONMENT PROGRAMME (UNEP). Proceedings of the Governing Council/Global Environment Ministerial Forum at its Twenty-Fifth Session. 16 - 20 Fev. 2009. Disponível em: < https://wedocs.unep.org/bitstream/ handle/20.500.11822/10623/K0950890\%20GC-25-17-Proceedings-FINAL. pdf? sequence $=1$ \&isAllowed $=\mathrm{y}>$. Acesso: 16/10/2018

UNITED NATIONS INDUSTRIAL DEVELOPMENT ORGANIZATION (UNIDO). Apresenta informações sobre a relação entre a UNIDO e a Convenção de Minamata. Disponível em: < https://www.unido.org/sites/default/files/2014-02/201312_mercury_final_ web_0.pdf >. Acesso: 16/10/2018

UNITED STATES Senate. Bush signs into law Obama-Murkowski-Allen bill to ban dangerous mercury exports. 15 Out. 2008. Disponível em: < https://www.epw.senate. gov/public/index.cfm/press-releases-democratic?ID = 87C5F3E6-802A-23AD-4135DADC42382459 > . Acesso: 16/10/2018

YANG, Tseming. The Minamata Convention on Mercury and the Future of Multilateral Environmental Agreement. Environmental Law Reporter. Santa Clara Univ. Legal Studies Research Paper, 2014 p. 1-15.

ZHENG, Siq; KAHN, Matthew. Understanding China's Urban Pollution Dynamics. Journal of Economic Literature, v. 51, n. 3, 2013, p. 731-772. 